\section{Patent Foramen Ovale and Stroke in Adolescents - to Close or Not to Close?}

\author{
Sónia Silva1*, Cláudia Teles Silva, Jacinta Fonseca², Cláudia \\ Melo $^{2}$, Mafalda Sampaio ${ }^{2}$ and Raquel Sousa ${ }^{2}$ \\ ${ }^{1}$ Department of Pediatrics, Centro Hospitalar Universitário de São João, \\ Porto, Portugal
}

${ }^{2}$ Department of Neuropediatrics, Centro Hospitalar Universitário de São João, Porto, Portugal

\begin{abstract}
Stroke is a rare condition in childhood and about half of the cases are due to an arterial ischemic event. Although the long list of known causes, many cases remain undetermined, so-called cryptogenic strokes. However, increasing evidence indicates that some of these cryptogenic cases can be a result of a paradoxical embolism via a Patent Foramen Ovale (PFO) with a right-to-left intracardiac shunt, but the exact contribution of PFO to stroke or stroke recurrence in childhood remains unclear. Considering this, as a second line of study, a transthoracic and transoesophageal echocardiogram should be done in all cases to rule out a possible right-to-left shunt, such as PFO. Optimal treatment for acute ischemic strokes in children is controversial, with lacking studies. Closure of PFO should be considered as a preventive measure depending on individual risk factors and anatomic features.

We present two cases of a 16-year-old boy and a 17-year-old girl who had an event of cerebral ischemia documented on MRI, and in whom was found a PFO with a shunt, with the remaining exhaustive etiologic investigation all negative. Both of them underwent percutaneous closure of the PFO.
\end{abstract}

Keywords: Patent foramen ovale; Pediatric arterial ischemic stroke; Right-to-left shunt; Stroke

*Corresponding author: Sónia Silva, Pediatrics, Centro Hospitalar Universitário de São João, Porto, Portugal, Tel: +351 913563106; E-mail: sonia_silva88@hotmail.com

Citation: Silva S, Silva CT, Fonseca J, Melo C, Sampaio M, et al. (2019) Patent Foramen Ovale and Stroke in Adolescents - to Close or Not to Close? J Neonatol Clin Pediatr 6: 041.

Received: December 06, 2019; Accepted: December 20, 2019; Published: December 27, 2019

Copyright: ( 2019 Silva S, et al. This is an open-access article distributed under the terms of the Creative Commons Attribution License, which permits unrestricted use, distribution, and reproduction in any medium, provided the original author and source are credited.

\section{Case Report}

A healthy 16 year-old boy, presented with neck, chest and right upper limb involuntary movements, followed by headache, vertigo, left tinnitus, nausea, vomiting, blurred vision, tongue tickling and paresthesia of right limbs, with multidirectional nystagmus, ataxia and right dysmetria on examination. There was a family history of stroke in his grandparents. Cerebral Computerized Tomography (CT) revealed a well delimited area of hypodensity located in the superior region of the right cerebellar hemisphere, suggesting a recent ischemic stroke. Cerebral Magnetic Resonance Imaging (MRI) showed bilateral acute ischemic lesions on the cerebellum, with normal vessels and arteries in the angio-MRI. At admission, electrocardiograph monitoring and Transthoracic Echocardiogram (TTE) normal. Basal Transcranial Doppler (TCD) with bubble test showed right-to-left shunt with and without Valsalva manoeuvre. Afterwards, an elective Transesophageal Echocardiogram (TEE) revealed a Patent Foramen Ovale (PFO) with shunt, and he was submitted to a percutaneous catheterization for closure of PFO five months after discharge.

A second case is a 17 year-old girl, with a previous history of migraine and under oral contraceptive, who presented with left brachiofacial hemiparesis, left visual neglect and dysarthria. Previously of that, she had 7 days of headache, with the same characteristics of her normal migraine. Her mother and sister had history of migraine too. CT scan showed an area of acute ischemia in the right frontal cortico-subcortical region, with an image suggestive of thrombus in the right Middle Cerebral Artery (MCA) and an important penumbra zone into its territory. She underwent intravenous recombinant tissue Plasminogen Activator (rtPA) and mechanical embolectomy after 3 hours of the initial presentation. The control CT scan had no hemorrhagic complications. MRI confirmedan acute ischemic event in the territory of MCA. TTE and TEE revealed a PFO with shuntand an ostium secundum interatrial communication. Basal TCD with bubble test confirmed the right-to-left shunt with Valsalva manoeuvre. A percutaneous catheterization with successful closure of PFO and the interatrial communication was performed during the admission.

Both patients underwent complete haematological and biochemical investigations, including coagulation abnormalities and genetic study for thrombophilia, autoimmune, inflammatory and infectious diseases, and doppler ultrasonography of lower limbs, all with normal results. Both patients were started on aspirin, and had complete resolution of symptoms at 18 months of follow-up.

\section{Discussion}

Stroke is a rare condition in childhood [1]. Acute Ischemic Strokes (AIS) accounts for about half of all strokes in children [1-2]. Although hospitalizations for AIS in children have been rising in the past decade, with the improvement of medical knowledge, it is likely to be underdiagnosed or misdiagnosed, because of the low level of suspicion and frequent presentation of subtle symptoms that mimic other diseases [1,2]. The most well described risk factors in pediatrics for AIS are congenital heart disease, sickle cell disease, fection and 
hypercoagulable states [1]. Cerebral or cervicalarteriopathy can be identified in $50 \%$ to $80 \%$ of cases, corresponding to an independent risk factor [3-5]. Multiple risk factors are present in as many as $25 \%$ of children with stroke, which means further investigations are warranted even when one risk factor has been identified [2].

In spite of the long list of known causes and risk factors, the term "cryptogenic stroke" is used to define stroke in $20-30 \%$ of children where the etiology remains undefined despite extensive investigations $[3,6]$. A possible explanation for some AIS in children considered cryptogenic might be a paradoxical embolism in the presence of a right-to-left shunt in the heart such as PFO, with the microemboli going through right atrium into the systemic cerebral circulation [6,7]. Different studies found that the prevalence of PFO among cryptogenic stroke patients is higher than in the general population (40-50\% versus $20-25 \%$ ) $[4,5,7]$. However, the exact rule of PFO to stroke or stroke recurrence in childhood remains unclear and this should be considered as a diagnosis of exclusion [3,7]. Venous thromboembolism, genetic coagulation disorders or atrial septal aneurysm seems to confer an additional risk to stroke in presence of a PFO $[1,3,4,6]$. An association between migraine and PFO has been suggested too [3].

There are several ways to investigate a suspected PFO, including TTE, TEE and TCD. TTE with colour doppler remains the initial mandatory investigation for the cardiac assessment of pediatric patients with stroke. TEE with color doppler is semi-invasive procedure, requiring sedation and esophageal intubation, but provides providing high-resolution pictures of the posteriorly left atrium and interatrial septum and is considered the gold standard to investigate the embolic source in stroke. TCD with bubble test detects particulate embolic material or gaseous microbubbles in the cerebral circulation in real time, but does not portray cardiac anatomy [3].

In the absence of age-appropriate safety data or dosing guidelines, children who present with AIS are sometimes treated outside of the recommended guidelines with rtPA or mechanical embolectomy, often extrapolated from data in adult stroke trials [1]. Anticoagulation and/or antiplatelet therapy can be used as prophylaxis. The risk and benefit likely by age and underlying stroke etiology, but again, in children there is a lack of definitive data $[1,4,6,7]$. In the absence of a deep vein thrombosis or known hypercoagulable state antiplatelet therapy is typically recommended. Modifiable risk factors should be aggressively addressed [4]. The percutaneous closure of PFO with intracardiac shunting to prevent recurrent stroke in children is controversial and should be individualized, based on significant shunting and risk factors. It is considered as a simple procedure with low risk. Patients with large shunts and those with a hypermobile interatrial septum receive particular benefit from PFO closure [6-8].

The mortality rate of AIS in children approaches $4 \%$; over $50 \%$ of survivors have persistent neurologic, cognitive or psychiatric deficits and nearly a third of patients develop epilepsy within the first decade after stroke [1-2]. The annual risk of stroke recurrence in patients with cryptogenic stroke is relatively low, about $1 \%$ to $2 \%$ per year, but that misrepresents what may be a significant accumulated lifetime risk [7].
With the presentation of those two cases we pretend to highlight the importance of a high level of suspicion of stroke in children with neurological symptoms. The earlier diagnosis in the second case of stroke (with more suspicious symptoms on presentation) and PFO allowed respectively the treatment with pharmacologic thrombolysis and mechanical embolectomy and the closure of PFO during the first days of admission. An exhaustive study to exclude all the possible causes of AIS should be done, and paradoxical embolism viaPFO withright-to-left shunt should be considered, as well as the execution of TEE. Research about the treatment and prophylaxis of recurrence of AIS in the pediatric population is lacking and should be a priority. Closure of PFO should be considered as a preventive measure depending on individual risk factors and anatomic features.

\section{Conflict of Interest}

No conflict of interest is declared by all authors.

\section{Patient Consent}

Parental/guardian consent obtained.

\section{References}

1. Numis AL, Fox CK (2014) Arterial ischemic stroke in children: Risk factors and etiologies. Curr Neurol Neurosci Rep 14: 422.

2. Tsze DS, Valente JH (2011) Pediatric stroke: a review. Emerg Med Int 2011: 734506 .

3. Khan R, Chan AK, Mondal TK, Paes BA (2016) Patent foramen ovale and stroke in childhood: A systematic review of the literature. Eur J Paediatr Neurol 20: 500-511.

4. Mackey J (2014) Evaluation and management of stroke in young adults. Continuum (Minneap Minn) 20: 352-369.

5. Bernard TJ, Goldenberg NA (2010) Pediatric arterial ischemic stroke. Hematol Oncol Clin North Am 24: 167-180.

6. Agnetti A, Carano N, Sani E, Tchana B, Allegri V, et al. (2006) Cryptogenic stroke in children: Possible role of patent foramen ovale. Neuropediatrics 37: 53-56.

7. Melkumova E, Thaler DE (2017) Cryptogenic stroke and patent foramen ovale risk assessment. Interv Cardiol Clin 6: 487-493.

8. Stortecky S, da Costa BR, Mattle HP, Carroll J, Hornung M, et al. (2015) Percutaneous closure of patent foramen ovale in patients with cryptogenic embolism: A network meta-analysis. Eur Heart J 36: 120-128. 
Citation: Silva S, Silva CT, Fonseca J, Melo C, Sampaio M, et al. (2019) Patent Foramen Ovale and Stroke in Adolescents - to Close or Not to Close? J Neonatol Clin Pediatr 6: 041.

- Page 3 of 3 • 


\section{If}

Advances In Industrial Biotechnology | ISSN: 2639-5665

Advances In Microbiology Research | ISSN: 2689-694X

Archives Of Surgery And Surgical Education | ISSN: 2689-3126

Archives Of Urology

Archives Of Zoological Studies | ISSN: 2640-7779

Current Trends Medical And Biological Engineering

International Journal Of Case Reports And Therapeutic Studies | ISSN: 2689-310X

Journal Of Addiction \& Addictive Disorders | ISSN: 2578-7276

Journal Of Agronomy \& Agricultural Science | ISSN: 2689-8292

Journal Of AIDS Clinical Research \& STDs | ISSN: 2572-7370

Journal Of Alcoholism Drug Abuse \& Substance Dependence | ISSN: 2572-9594

Journal Of Allergy Disorders \& Therapy | ISSN: 2470-749X

Journal Of Alternative Complementary \& Integrative Medicine | ISSN: 2470-7562

Journal Of Alzheimers \& Neurodegenerative Diseases | ISSN: 2572-9608

Journal Of Anesthesia \& Clinical Care | ISSN: 2378-8879

Journal Of Angiology \& Vascular Surgery | ISSN: 2572-7397

Journal Of Animal Research \& Veterinary Science | ISSN: 2639-3751

Journal Of Aquaculture \& Fisheries | ISSN: 2576-5523

Journal Of Atmospheric \& Earth Sciences | ISSN: 2689-8780

Journal Of Biotech Research \& Biochemistry

Journal Of Brain \& Neuroscience Research

Journal Of Cancer Biology \& Treatment | ISSN: 2470-7546

Journal Of Cardiology Study \& Research | ISSN: 2640-768X

Journal Of Cell Biology \& Cell Metabolism | ISSN: 2381-1943

Journal Of Clinical Dermatology \& Therapy | ISSN: 2378-8771

Journal Of Clinical Immunology \& Immunotherapy | ISSN: 2378-8844

Journal Of Clinical Studies \& Medical Case Reports | ISSN: 2378-8801

Journal Of Community Medicine \& Public Health Care | ISSN: 2381-1978

Journal Of Cytology \& Tissue Biology | ISSN: 2378-9107

Journal Of Dairy Research \& Technology | ISSN: 2688-9315

Journal Of Dentistry Oral Health \& Cosmesis | ISSN: 2473-6783

Journal Of Diabetes \& Metabolic Disorders | ISSN: 2381-201X

Journal Of Emergency Medicine Trauma \& Surgical Care | ISSN: 2378-8798

Journal Of Environmental Science Current Research | ISSN: 2643-5020

Journal Of Food Science \& Nutrition | ISSN: 2470-1076

Journal Of Forensic Legal \& Investigative Sciences | ISSN: 2473-733X

Journal Of Gastroenterology \& Hepatology Research | ISSN: 2574-2566
Journal Of Genetics \& Genomic Sciences | ISSN: 2574-2485

Journal Of Gerontology \& Geriatric Medicine | ISSN: 2381-8662

Journal Of Hematology Blood Transfusion \& Disorders | ISSN: 2572-2999

Journal Of Hospice \& Palliative Medical Care

Journal Of Human Endocrinology | ISSN: 2572-9640

Journal Of Infectious \& Non Infectious Diseases | ISSN: 2381-8654

Journal Of Internal Medicine \& Primary Healthcare | ISSN: 2574-2493

Journal Of Light \& Laser Current Trends

Journal Of Medicine Study \& Research | ISSN: 2639-5657

Journal Of Modern Chemical Sciences

Journal Of Nanotechnology Nanomedicine \& Nanobiotechnology | ISSN: 2381-2044

Journal Of Neonatology \& Clinical Pediatrics | ISSN: 2378-878X

Journal Of Nephrology \& Renal Therapy | ISSN: 2473-7313

Journal Of Non Invasive Vascular Investigation | ISSN: 2572-7400

Journal Of Nuclear Medicine Radiology \& Radiation Therapy | ISSN: 2572-7419

Journal Of Obesity \& Weight Loss | ISSN: 2473-7372

Journal Of Ophthalmology \& Clinical Research | ISSN: 2378-8887

Journal Of Orthopedic Research \& Physiotherapy | ISSN: 2381-2052

Journal Of Otolaryngology Head \& Neck Surgery | ISSN: 2573-010X

Journal Of Pathology Clinical \& Medical Research

Journal Of Pharmacology Pharmaceutics \& Pharmacovigilance | ISSN: 2639-5649

Journal Of Physical Medicine Rehabilitation \& Disabilities | ISSN: 2381-8670

Journal Of Plant Science Current Research | ISSN: 2639-3743

Journal Of Practical \& Professional Nursing | ISSN: 2639-5681

Journal Of Protein Research \& Bioinformatics

Journal Of Psychiatry Depression \& Anxiety | ISSN: 2573-0150

Journal Of Pulmonary Medicine \& Respiratory Research | ISSN: 2573-0177

Journal Of Reproductive Medicine Gynaecology \& Obstetrics | ISSN: 2574-2574

Journal Of Stem Cells Research Development \& Therapy | ISSN: 2381-2060

Journal Of Surgery Current Trends \& Innovations | ISSN: 2578-7284

Journal Of Toxicology Current Research | ISSN: 2639-3735

Journal Of Translational Science And Research

Journal Of Vaccines Research \& Vaccination | ISSN: 2573-0193

Journal Of Virology \& Antivirals

Sports Medicine And Injury Care Journal | ISSN: 2689-8829

Trends In Anatomy \& Physiology | ISSN: 2640-7752

Submit Your Manuscript: http://www.heraldopenaccess.us/Online-Submission.php 